\title{
Divergência genética entre progênies de Pinus caribaea var. caribaea com base em caracteres quantitativos
}

\author{
Janete Motta da Silva ${ }^{1}$, Ananda Virginia de Aguiar ${ }^{2}$, Edson Seizo Mori ${ }^{3}$, Mario Luiz Teixeira de Moraes $^{3}$ \\ ${ }^{1}$ Universidade Estadual Paulista "Júlio de Mesquita Filho", Faculdade de Engenharia de Ilha Solteira, Av. Brasil Centro, 56, CEP 15.385-000, Ilha Solteira, SP, Brasil \\ ${ }^{2}$ Embrapa Florestas - Estrada da Ribeira, km 111, CEP 83411-000 Colombo, PR, Brasil \\ 3Universidade Estadual Paulista "Júlio de Mesquita Filho", Faculdade de Ciências Agronômicas, Departamento de Produção Vegetal, R. Dr. José Barbosa de \\ Barros, 1780, CEP 18610-307 Botucatu, SP, Brasil
}

*Autor correspondente:

janetemottasilva@gmail.com

Termos para indexação:

Parâmetros genéticos

Divergência genética

Pinheiros tropicais

Teste de progênies

Index terms:

Genetic parameters

Genetic divergence

Tropical pines

Progeny trial

Histórico do artigo:

Recebido em 02 fev 2011

Aprovado em 02 mar 2012

Publicado em 30 mar 2012
Resumo - O objetivo desse trabalho foi quantificar a dissimilaridade genética entre progênies de $P$. caribaea var. caribaea para identificar genitores divergentes, visando gerar genótipos mais produtivos e avaliar a variabilidade total por meio de alguns caracteres fenotípicos de importância comercial. Assim, um teste de progênies de $P$. caribaea var. caribaea foi implantado em delineamento experimental látice $10 \times 10$ triplo, com 99 progênies e uma testemunha comercial em Selvíria, MS. Foram avaliados os caracteres quantitativos antes e após desbaste aos 14 anos, tais como: altura total de plantas $(\mathrm{m})$, diâmetro à altura do peito - DAP $(\mathrm{cm})$; volume $\left(\mathrm{m}^{3}\right.$ árvore $\left.{ }^{-1}\right)$; forma do fuste das árvores, densidade básica da madeira, na altura do DAP - DBM-1, e na metade da altura da árvore - DBM-2 $\left(\mathrm{g} \mathrm{cm}^{-3}\right)$; e sobrevivência das progênies (\%). Houve baixa divergência genética entre as progênies de $P$. caribaea var. caribaea. O DAP foi o caráter que mais contribuiu para a divergência genética entre as progênies, tanto antes quanto depois do desbaste. As informações geradas com base na distância generalizada de Mahalanobis e o agrupamento das progênies pelo método de Tocher serão usadas para definir as estratégias a serem adotadas em futuros programas de melhoramento e conservação genética desta espécie. under quantitative characters

\begin{abstract}
The objective of this research was to quantify the genetic dissimilarity among P.caribaea var. caribaea progenies to identify divergent parents aiming to generate highly productive genotypes and to evaluate the total variability by phenotypic characters of commercial importance. The progeny trial of P. caribaea var. caribaea was set up through $10 \times 10$ triple lattice design, with 99 progenies and a commercial control in Selvíria, MS, Brazil. We have evaluated quantitative characters before and after thinning procedures such as: total plant height (m), diameter at breast height (dbh) (cm); wood volume (m3 tree-1), stem form, wood density at dbh and wood density at the middle of the total height of tree stem ( $\mathrm{g} \mathrm{cm}-3)$, and survival of progenies $(\%)$. There was low genetic divergence among P. caribaea var. caribaea progenies. The diameter at breast height was the character that most contributes to genetic diversity among progenies, for both before and after thinning. The information of Mahalanobis distance and the clustering of progenies by Tocher's method will be important to define the future strategies for breeding programs and genetic conservation of the species.
\end{abstract}




\section{Introdução}

No gênero Pinus, encontra-se algumas das espécies mais plantadas no mundo para produção de madeira serrada, papel e celulose. As espécies de Pinus mais importantes para o Brasil são provenientes principalmente da América do Norte e América Central (Fier \& Kikuti, 1993). As características morfológicas e silviculturais da madeira de Pinus, assim como a introdução de espécies tropicais de $P$. caribaea, têm promovido expansão da distribuição geográfica das florestas plantadas com este gênero no Brasil. As áreas de plantio, antes restritas à região Sul, têm-se ampliado, atingindo as regiões Sudeste e Centro-Oeste e algumas áreas das regiões Norte e Nordeste (Silva Júnior, 1993).

A área total com plantio de Pinus no Brasil até final de 2010 era de 1,76 milhões de hectares (Anuário..., 2011). Nas regiões Norte e Centro do estado de São Paulo, onde se situam os cerrados, caracterizados por inverno e primavera secos e solos pobres, as espécies que melhor se adaptaram foram as de origem tropical: $P$. caribaea var. hondurensis, $P$. caribaea var. caribaea, $P$. caribaea var. bahamensis, Pinus oocarpa e Pinus kesiya.

As variedades de $P$. caribaea apresentam excelentes qualidades a serem exploradas para produção de papel, madeira, resinas, etc. $P$. caribaea var. caribaea, conhecido comumente como pinho caribenho, é o único pinheiro tropical que cresce naturalmente em baixas altitudes (Francis, 1992).

A madeira de $P$. caribaea var. caribaea tem estrutura grosseira com fibras verticais; cor marrom avermelhada ou marrom amarelada; anéis de crescimento largos no lenho outonal e cerne não formado até a idade dos 15 anos (Wang et al., 1999). Segundo os autores, a densidade básica da madeira seca foi de $0,47 \mathrm{~g} \mathrm{~cm}^{-3}$ aos 10 anos, e $0,58 \mathrm{~g} \mathrm{~cm}^{-3}$ aos 15 anos, considerada de moderadamente pesada a pesada. A madeira é apropriada para produção de pasta sulfúrica na fabricação de papéis reforçados (Wang et al., 1999).

Algumas populações naturais de $P$. caribaea var. caribaea foram conduzidas para produção in situ (Zheng \& Ennos, 1999). Genótipos de P. caribaea var. caribaea foram selecionados para estabelecer pomares de sementes dentro da área de ocorrência natural (Cuba), a fim de fornecer sementes para plantações comerciais. Além disso, essas sementes selecionadas foram usadas para serem introduzidas em localizações exóticas (ex situ), para estabelecer plantações na Austrália e China. Os estudos de procedência desta espécie, em vários países, tem comprovado que a base genética da variedade caribaea é estreita (Zheng et al., 1997; Missio et al., 2004; Silva, 2005).

A avaliação da divergência genética entre progênies ou populações, com base em caracteres quantitativos, é importante para direcionar a estratégia de melhoramento a ser adotada. Com base na identificação do desempenho do material genético é possível explorar a recombinação dos genes e a heterose produzida a partir de cruzamentos controlados (Humphreys, 1991). Quando se tem uma população com base genética estreita, orienta-se identificar grupos de progênies divergentes geneticamente para efetuar cruzamentos controlados visando ampliar a variação genética disponível nestes ensaios e contribuir para a maximização da sua produtividade. Portanto, as informações sobre a dissimilaridade genética possibilitam prever os possíveis cruzamentos controlados que possam gerar materiais genéticos mais produtivos.

Com base na análise da distância genética também é possível identificar os materiais genéticos que servem como elo entre a conservação e a utilização dos recursos genéticos disponíveis. Sua estimativa pode informar a respeito da organização do germoplasma, aumentar a eficiência da amostragem de genótipos, auxiliar na definição de cruzamentos artificiais, na incorporação de genes de germoplasma exótico e até na recomendação de cultivares para determinada região, quando o objetivo é aumentar a base genética das cultivares (Vieira et al., 2007).

Neste trabalho foi quantificada a dissimilaridade genética entre progênies de Pinus caribaea var. caribaea para identificar os genitores divergentes que possibilitarão gerar genótipos mais produtivos e foi avaliada a contribuição de alguns caracteres fenotípicos para a variabilidade total, como etapa inicial de um programa de melhoramento.

\section{Material e métodos}

O estudo foi realizado em um teste de progênies de $P$. caribaea var. caribaea instalado em janeiro de 1989 na Fazenda de Ensino, Pesquisa e Extensão da Faculdade de Engenharia de Ilha Solteira - FEPE/FEIS/UNESP, localizada no município de Selvíria, MS.

As sementes das progênies utilizadas foram cedidas pelo Instituto de Pesquisas e Estudos Florestais (IPEFESALQ/USP), Piracicaba, SP, originadas de um pomar 
de sementes clonal do Centro de Conservação Genética e Melhoramento de Pinheiros Tropicais - CCGMPT, Aracruz, ES (coordenadas 1949' S e 40 $16^{\circ}$ ' O, altitude $50 \mathrm{~m}$ ). A testemunha comercial que compõe o teste de progênies é proveniente dos plantios comerciais da Duratex S.A., Agudos, SP (coordenadas $22^{\circ} 22^{\prime} \mathrm{S}$ e $48^{\circ} 52^{\prime} \mathrm{O}$, altitude $550 \mathrm{~m}$ ).

Aárea experimental se localiza na latitude de $20^{\circ} 20^{\prime} \mathrm{S}$, longitude de $51^{\circ} 23^{\prime} \mathrm{O}$ e altitude de $370 \mathrm{~m}$, clima do tipo Aw, pela classificação de Köppen, temperatura média anual de $24,5^{\circ} \mathrm{C}$, precipitação média anual de 1232,2 mm, umidade média anual de $64,8 \%$ e insolação média de 7,3 horas dia ${ }^{-1}$ (Hernandez et al., 1995). O solo local foi classificado como latossolo vermelho distrófico típico argiloso, A moderado, hipidistrófico, álico, caulinítico, férrico, compactado, muito profundo, moderadamente ácido (LVd) (Demattê, 1980; Sistema..., 1999).

O delineamento experimental utilizado para instalação do teste de progênies de polinização livre de $P$. caribaea var. caribaea foi o látice quadrado, $10 \times 10$, triplo, com uma testemunha comercial e 99 tratamentos (progênies), três repetições, parcelas lineares com dez plantas no espaçamento de $3 \mathrm{~m} \times 3 \mathrm{~m}$.

Aos 14 anos após o plantio, realizou-se um desbaste com 50\% de intensidade, baseado no índice multi-efeitos estimado para o caráter DAP (Resende \& Higa, 1994), permanecendo cinco plantas por parcela.

A avaliação de dados quantitativos foi realizada em cinco situações:

A) Antes do desbaste - aos 14 anos após o plantio: foram avaliadas todas as árvores de cada parcela $(n=10$ plantas por parcela), com relação aos caracteres: altura total de plantas $(\mathrm{m})$; diâmetro à altura do peito - DAP (cm); forma do fuste das árvores, obtida a partir de escala de notas proposta por Kageyama (1977); volume cilíndrico $\left(\mathrm{m}^{3}\right.$ árvore $\left.{ }^{-1}\right)$ e sobrevivência das plantas $(\%)$.

B) Árvores desbastadas - aos 14 anos após o plantio: após a realização da situação A, realizou-se o desbaste. De cada árvore desbastada foram retirados dois discos para determinação da densidade básica da madeira, sendo um na altura do DAP (DBM-1) e outro na metade da altura total da árvore (DBM-2). A DBM foi obtida pela metodologia da balança hidrostática, conforme metodologia proposta por Foelkel et al. (1971). Na situação B foram avaliados os caracteres: altura total de plantas $(\mathrm{m}), \mathrm{DAP}(\mathrm{cm})$, forma do fuste, volume cilíndrico $\left(\mathrm{m}^{3}\right.$ árvore $\left.^{-1}\right), \mathrm{DBM}-1$ e DBM-2 $\left(\mathrm{g} \mathrm{cm}^{-3}\right)$.
C, D e E) Árvores remanescentes após o desbaste: aos 14, 15 e 16 anos após o plantio, foram avaliados os caracteres: altura total de plantas (m); DAP (cm); e volume cilíndrico $\left(\mathrm{m}^{3}\right.$ árvore $\left.^{-1}\right)$. A forma do fuste das árvores foi avaliada apenas aos 14 anos (situação C).

O volume cilíndrico foi obtido pela seguinte expressão:

$$
V=\frac{\pi}{4}(D A P)^{2} \cdot A L T \cdot \bar{q}
$$

em que:

$$
\overline{\mathrm{q}}=\frac{\mathrm{D} 1 / 2 \mathrm{H}_{\mathrm{c}}}{\operatorname{DAP}_{\mathrm{c}}}
$$

Sendo: $\overline{\mathrm{q}}=$ quociente de forma, obtido para cada uma das parcelas, com base nas árvores desbastadas;

$\mathrm{D}^{1} / 2 \mathrm{H}_{\mathrm{cc}}=$ medida feita no disco obtido no diâmetro na metade da altura total da árvore, com casca;

$\mathrm{DAP}_{\mathrm{cc}}=$ medida feita no disco obtido na altura do DAP, com casca.

A diversidade genética entre as progênies de $P$. caribaea var. caribaea foi estimada pela distância generalizada de Mahalanobis $\left(\mathrm{D}^{2}\right)$, segundo metodologia proposta por Cruz \& Carneiro (2003). As distâncias genéticas de Mahalanobis $\left(\mathrm{D}^{2}\right)$ foram estimadas com base nos caracteres quantitativos avaliados nas situações A, B, C, D e E. As análises foram realizadas com o uso do programa computacional GENES, conforme Cruz (2001).

A partir das matrizes de dissimilaridades, obtidas na distância de Mahalanobis $\left(\mathrm{D}^{2}\right)$, foi aplicado o método de otimização de Tocher para obter grupos de progênies homogêneas, segundo Cruz \& Regazzi (2001).

Para estimar a contribuição relativa de cada caráter para a divergência genética empregou-se metodologia proposta por Singh (1981), baseado na partição do total das estimativas das distâncias de Mahalanobis $\left(\mathrm{D}^{2}\right)$, considerando todos os possíveis pares de progênies, para as partes referentes a cada caráter.

\section{Resultados e discussão}

As estimativas das medidas de dissimilaridade, obtidas pela distância generalizada de Mahalanobis $\left(\mathrm{D}^{2}\right)$, foram baixas (Tabela 1) se comparadas com os valores obtidos para $P$. caribaea var. hondurensis (Moraes, 2001) e P. caribaea var. bahamensis 
(Missio et al., 2007), estudados na FEPE/FEIS/ UNESP. Isso sugere que existe pouca diversidade genética no material estudado.

Porém, apesar da baixa variabilidade genética observada para este teste de progênies, a análise de divergência genética constatou a formação de grupos geneticamente divergentes (Tabela 1).

Com a distância generalizada de Mahalanobis $\left(\mathrm{D}^{2}\right)$ foi possível obter as distâncias genéticas máxima, mínima e média entre pares de progênies. Na situação A, as progênies 6 e 57 tiveram a máxima distância genética $(0,042214)$, e as progênies 54 e 91 tiveram a mínima distância $(0,000002)$, sendo a distância média 0,003448 . Na situação $\mathrm{B}$, a máxima distância genética ocorreu entre as progênies 57 e 100, a mínima distância entre as progênies 49 e 94, e a média foi 0,512737. As progênies 23 e 97 tiveram a máxima distância genética nas situações $\mathrm{C}, \mathrm{D}$ e E (0,000022; 0,000184 e 0,000051, respectivamente). $\mathrm{Na}$ situação $\mathrm{C}$, a mínima distância foi entre as progênies 15 e $26(0,146569)$, e a distância média foi de 0,146569 . Na situação $\mathrm{D}$ as progênies 4 e 40 tiveram a distância mínima $(0,231642)$ e a distância média foi 0,077429 .

Nos próximos ciclos de seleção, para manter e/ou aumentar a variabilidade genética das populações de melhoramento, cruzamentos entre genótipos de grupos heterogêneos devem ser priorizados. O direcionamento de cruzamentos entre as progênies que apresentaram maior divergência pode ser importante também para preservar a variabilidade genética (Ferraz Filho et al., 2008), principalmente para esta população que apresentou baixa variabilidade genética entre as progênies.

Tabela 1. Estimativas de medidas de dissimilaridade (Mahalanobis - $\mathrm{D}^{2}$ ) entre pares de progênies $P$. caribaea var. caribaea, com base em caracteres fenotípicos.

\begin{tabular}{cccccc}
\hline Situação & $\mathbf{D}^{\mathbf{2}}$ Máxima & Progênies & $\mathbf{D}^{\mathbf{2}}$ Mínima & Progênies & D $^{\mathbf{2}}$ Média \\
\hline A (14 anos) & 0,042214 & 6 e 57 & 0,000002 & 54 e 91 & 0,003448 \\
B (14 anos) & 7,423162 & 57 e 100 & 0,000499 & 49 e 94 & 0,512737 \\
C (14 anos) & 2,062359 & 23 e 97 & 0,000022 & 15 e 26 & 0,146569 \\
D (15 anos) & 2,141006 & 23 e 97 & 0,000184 & 4 e 40 & 0,231642 \\
E (16 anos) & 1,082639 & 23 e 97 & 0,000051 & 26 e 32 & 0,077429 \\
\hline
\end{tabular}

A- Antes do desbaste aos 14 anos após o plantio; Árvores desbastadas aos 14 anos após o plantio; C- Árvores remanescentes ao desbaste aos 14 anos após o plantio; D- Um ano após o desbaste aos 15 anos após o plantio; E- Dois anos após o desbaste aos 16 anos após o plantio.

Antes do desbaste (situação A) foram observados os valores de menor magnitude para as distâncias genéticas médias e, consequentemente, a menor divergência entre as progênies $\left(\mathrm{D}^{2}=0,003448\right)$ (Tabela 1). As árvores desbastadas tiveram distância média mais expressiva (B, 0,512737) que as demais situações, por reunir os materiais mais divergentes; já as árvores remanescentes $(\mathrm{C}, 0,146569)$ tiveram divergência maior do que antes do desbaste (A, 0,003448), indicando que a seleção conservou os grupos mais divergentes existentes no teste de progênies.

Após o desbaste, houve redução da $\mathrm{D}^{2}$ observada no primeiro $(\mathrm{D}, 0,231642)$ para o segundo ano $(\mathrm{E}$, 0,077429). Isso pode ser explicado pela redução da divergência genética entre as progênies, o que evidentemente ocorre em função da seleção efetuada no teste de progênies. Esta redução das distâncias genéticas entre progênies após o desbaste também foi observada em P. caribaea var. bahamensis (Missio et al., 2007).

O caráter de maior contribuição relativa para a obtenção das distâncias genéticas entre as progênies foi o DAP nas situações $A, B, C$, e E, sendo que os demais caracteres contribuíram em proporção menos expressiva (Tabela 2). A princípio, este caráter pode ser priorizado durante a aplicação das estratégias de seleção, principalmente para a finalidade de produção de madeira.

$\mathrm{Na}$ situação $\mathrm{D}$, um ano após o desbaste, o volume foi o caráter com a maior contribuição para a divergência, 85,39\%, seguido pelo DAP 
com $12,02 \%$ e depois a altura com $2,51 \%$. Dois anos após o desbaste (situação E) houve equilíbrio de contribuição relativa entre volume $(47,68 \%)$ e DAP $(51,19 \%)$, sendo que a altura participou com apenas $1,13 \%$ (Tabela 2 ).

Em relação à contribuição relativa de cada caráter para a divergência genética, considerando os caracteres de crescimento, a altura apresentou a menor contribuição relativa para a diversidade genética entre as progênies, e somente na situação A o volume teve contribuição inferior (31\%) à altura (44\%) (Tabela 2). Portanto, durante a aplicação do critério de seleção, o DAP deve ser considerado, principalmente, por ser um caráter facilmente mensurável e que detém menor porcentagem de erro durante sua avaliação.

A forma do fuste teve, em ordem decrescente, a segunda (A e C) e terceira (B) contribuição para a divergência genética entre as progênies nas situações em que foi avaliada (A, B e C). Este caráter e o volume cilíndrico são importantes quando a finalidade do melhoramento visa, principalmente, a produção de maneira para processamento mecânico. Para os ciclos de seleção subsequentes, o caráter que detém maior divergência genética pode garantir ganhos genéticos mais expressivos que os demais caracteres.

Tabela 2. Contribuição relativa dos caracteres avaliados na Situação A para a diversidade genética do testes de progênies de $P$. caribaea var. caribaea, em Selvíria, MS.

\begin{tabular}{cccccc}
\hline \multirow{2}{*}{ Caracteres } & \multicolumn{5}{c}{ Contribuição relativa dos caracteres (\%) } \\
\cline { 2 - 5 } & A (14 anos) & B (14 anos) & C (14 anos) & D (15 anos) & E (16 anos) \\
\hline Altura $(\mathrm{m})$ & 0,44 & 0,03 & 0,10 & 2,52 & 1,13 \\
DAP $(\mathrm{cm})$ & 89,02 & 95,81 & 83,37 & 12,09 & 51,19 \\
Forma & 10,24 & 0,73 & 11,41 & - & - \\
Volume $\left(\mathrm{m}^{3}\right.$ árv. $\left.^{-1}\right)$ & 0,31 & 2,13 & 5,12 & 85,39 & - \\
DBM-1 $\left(\mathrm{g} \mathrm{cm}^{-3}\right)$ & - & 1,25 & - & - & - \\
DBM-2 $\left(\mathrm{g} \mathrm{cm}^{-3}\right)$ & - & 0,05 & - & - & - \\
\hline
\end{tabular}

DAP- diâmetro à altura do peito; DBM-1- densidade básica da madeira, na altura do DAP e DBM-2- densidade básica da madeira na metade da altura da árvore.

Após a obtenção da dissimilaridade genética entre as progênies, foi aplicado o método de agrupamento visando o reconhecimento de grupos homogêneos. $\mathrm{O}$ método de otimização de Tocher aplicado à situação A (antes do desbaste) separou as progênies em 13 grupos (Tabela 3). Cerca de $35 \%$ das progênies fazem parte do grupo I. Por serem mutuamente excludentes, recomenda-se que seja feito o cruzamento entre progênies de grupos diferentes para a obtenção de híbridos mais heteróticos, como, por exemplo, as que apresentaram a maior $\mathrm{D}^{2}: 6$ (grupo 13) e 57 (grupo 10). Com base nesta análise são obtidos parâmetros para identificação de genitores que, quando cruzados, possibilitam maior efeito heterótico na progênie (Carvalho et al., 2003). Segundo Dias (1994), o conhecimento dos pares de progênies de maior diversidade orienta o processo de hibridação. Assim, os pares mais divergentes devem ser utilizados para a geração de híbridos mais heteróticos, enquanto os menos divergentes, diferenciados basicamente pelo gene a ser transferido, permitem recuperar o genitor recorrente mais rapidamente por meio de retrocruzamento.

$\mathrm{Na}$ situação B, as progênies foram agrupadas em quatro grupos distintos (Tabela 4), das quais $67 \%$ se enquadram no grupo I. As progênies que apresentaram a maior diversidade genética estão nos grupos II (progênie 100) e IV (progênie 57). Na situação $\mathrm{C}$ ocorreu a formação de seis grupos. Das 99 progênies 62 foram agrupadas no grupo I (Tabela 5), sendo que as progênies mais divergentes encontram-se nos grupos III (progênie 23) e V (progênie 97). 
Tabela 3. Formação de grupos com base no método de Tocher entre os caracteres altura, DAP, forma e volume estudados na situação A em progênies de P. caribaea var. caribaea, em Selvíria, MS.

\begin{tabular}{ccc}
\hline Grupo & Progênies & Total \\
\hline I & $54-91-60-61-47-95-96-18-26-78-45-15-44-40-8-87-28-1-2-88-27-67-10-66-31-3-82-94-36-$ & 35 \\
II & $64-79-77-13-69-72$ & 16 \\
III & $83-93-14-38-19-43-51-33-89-65-52-24-74-70-39-22$ & 10 \\
IV & $29-98-49-16-25-32-48-53-35-21$ & 12 \\
V & $46-99-37-12-81-58-92-100-50-11-4-63$ & 5 \\
VI & $68-85-71-75-90$ & 6 \\
VII & $5-59-34-7-73-84$ & 6 \\
VIII & $41-55-86-62-56-97$ & 4 \\
IX & $76-80-20-9$ & 2 \\
X & $23-42$ & 1 \\
XI & 57 & 1 \\
XII & 17 & 1 \\
XIII & 30 & 1 \\
\hline
\end{tabular}

Situação A: análise feita antes do desbaste, aos 14 anos após o plantio.

Tabela 4. Formação de grupos com base no método de aglomeração: otimização de Tocher, entre os caracteres altura, DAP, forma, volume, DBM-1 e DBM-2, estudados na situação B, em progênies de P. caribaea var. caribaea, em Selvíria, MS.

\begin{tabular}{ccc}
\hline Grupo & Progênies & Total \\
\hline & $49-94-91-15-1-17-41-59-40-93-2-10-69-79-50-64-26-7-38-71-5-73-68-95-66-87-60-47-27-$ & \\
I & $61-16-53-65-35-72-84-18-33-31-21-78-12-24-99-4-67-6-28-70-43-85-48-96-74-36-39-20-$ & 67 \\
& $30-89-45-9-8-29-92-25-51-77$ & 14 \\
II & $3-56-55-63-37-46-88-75-86-54-81-90-58-100$ & 18 \\
III & $14-98-23-52-22-80-44-82-13-34-76-32-19-97-83-11-62-42$ & 1 \\
IV & 57 & 5 \\
\hline
\end{tabular}

Situação B: análise feita nas árvores desbastadas, aos 14 anos.

Tabela 5. Formação de grupos com base no método de aglomeração: otimização de Tocher, entre os caracteres altura, DAP, forma e volume, estudados na situação C, em progênies de P. caribaea var. caribaea, em Selvíria, MS.

\begin{tabular}{ccc}
\hline Grupo & Progênies & Total \\
\hline & $15-26-87-77-45-82-91-51-61-52-8-4-84-31-53-10-16-54-19-27-81-42-58-36-32-89-14-72-$ & \\
I & $78-2-96-48-40-24-22-1-83-79-94-75-88-80-69-57-28-70-35-95-66-67-49-60-76-43-33-9-74-$ & 62 \\
& $98-64-63-100-73$ & 25 \\
II & $25-90-44-99-47-37-68-29-46-12-85-92-30-21-18-71-55-86-56-5-13-50-34-59-41$ & 8 \\
III & $38-93-39-17-65-20-3-23$ & 3 \\
IV & $11-62-6$ & 1 \\
V & 97 & 1 \\
VI & 7 & \\
\hline
\end{tabular}

Situação C: análise feita nas árvores remanescentes ao desbaste, aos 14 anos. 
Tabela 6. Formação de grupos com base no método de aglomeração: otimização de Tocher, entre os caracteres altura, DAP e volume, estudados na situação D, em progênies de P. caribaea var. caribaea, em Selvíria, MS.

\begin{tabular}{ccc}
\hline Grupo & Progênies & Total \\
\hline I & $4-40-79-98-64-44-47-21-87-29-77-85-90-53-63-31-32-51-100-26-68-7-15-37-92-99-60-66-$ & 35 \\
II & $55-58-82-86-81-49-75$ & 34 \\
III & $12-46-59-18-34-95-5-36-73-91-42-41-89-45-16-48-52-83-84-24-10-27-19-54-72-94-57-96-$ & 9 \\
IV & $61-76-70-1-69-67$ & 5 \\
V & $33-39-17-43-22-78-88-2-80$ & 4 \\
VI & $14-35-28-74-9$ & 4 \\
VII & $20-38-93-65$ & 3 \\
VIII & $30-71-25-13$ & 2 \\
IX & $11-50-6$ & 2 \\
X & $8-56$ & 2 \\
\hline
\end{tabular}

Situação D: análise feita um ano após o desbaste, aos 15 anos.

Tabela 7. Formação de grupos com base no método de aglomeração: otimização de Tocher, entre os caracteres altura, DAP e volume, estudados na situação E, em progênies de P. caribaea var. caribaea, em Selvíria, MS.

\begin{tabular}{ccc}
\hline Grupo & Progênies & Total \\
\hline I & $26-32-31-15-40-79-66-51-60-92-37-63-98-64-4-100-34-29-87-77-25-85-55-68-36-82-95-5-$ & \\
& $7-47-99-21-59-12-46-41-86-13-30-90-44-53-73-28-27-16-18-42-81-58-45-75-91-52-89-48-$ & 58 \\
II & $83-54$ & 32 \\
III & $72-96-80-57-94-70-67-69-1-76-22-2-88-24-9-93-43-78-61-10-19-38-74-49-20-39-84-8-35-$ & 5 \\
IV & $14-65-17$ & 3 \\
V & $11-50-6-62-71$ & 1 \\
VI & $3-23-33$ & 1 \\
\hline
\end{tabular}

Situação E: análise feita dois anos após o desbaste, aos 16 anos.

Na situação D (Tabela 6), as progênies foram agrupadas em dez grupos, sendo que as mais similares, a 4 e a 40, estão no grupo I, e as mais divergentes estão nos grupos IX (progênie 23) e X (progênie 97). O grupo I agrupa 35 progênies, o grupo II agrupa 34, e as 31 progênies restantes se distribuem nos outros oito grupos.

Na situação E, em relação à otimização de Tocher (Tabela 7) foram formados seis grupos. Dentre as 100 progênies estudadas, 58 progênies estão no grupo I, 32 progênies no grupo II, e o restante se distribuiu em outros quatro grupos. As progênies mais similares (26 e 32) encontram-se no grupo I, enquanto que as mais divergentes estão nos grupos IV (progênie 23) e VI (progênie 97).

Em espécies alógomas, a escolha correta de genitores e o planejamento de cruzamento podem otimizar a utilização de genes favoráveis $\mathrm{e}$, consequentemente, maximizar a heterose a partir do cruzamento de indivíduos com bons caracteres de produção e com certo grau de divergência genética, possibilitando a obtenção de cultivares superiores (Negreiros et al., 2008). Para $P$. caribaea var. caribaea os cruzamentos entre indivíduos divergentes poderão ser direcionados para a combinação de características produtivas 
e tecnológicas da madeira e para a obtenção de genótipos com maior potencial de adaptação a condições ambientais adversas.

De maneira geral, ao comparar os agrupamentos obtidos nas cinco situações analisadas, constata-se que as progênies não foram agrupadas da mesma forma em todas as situações. No entanto, ocorreu a coincidência de progênies em grupos contrastantes. Como esperado, na situação A, foi considerado um maior número de plantas por progênie, o que contribuiu para a obtenção de mais grupos de progênies divergentes. Apesar de ter sido aplicado uma intensidade de seleção de $50 \%$ (situações C, D e E), a representação da maior parte dessa divergência foi mantida. Para estratégias de melhoramento futuras devem ser considerados os agrupamentos obtidos nas situações D e E, nas quais se encontram os materiais remanescentes que serão fonte de sementes para os testes de progênies das gerações de melhoramento subsequentes. As informações obtidas no presente trabalho nortearão a seleção de genitores para os cruzamentos controlados e a obtenção de maior ganho genético.

Os indivíduos mais contrastantes e produtivos obtidos a partir do agrupamento de Tocher serão selecionados para cruzamentos de acordo com a estratégia de seleção adotada. Dentre os delineamentos de cruzamentos mais adequados para programas em que a estratégia de seleção adotada é a seleção recorrente recíproca (SSR), que visa o melhoramento do híbridos em ciclos subsequentes, podem ser citados: os policruzamentos (progênies de meios irmãos interpopulacionais); os de pares simples (progênies de irmãos germanos interpopulacionais); o fatorial desconexo (progênies de meios irmãos e irmãos germanos interpopulacionais) e o dialélico parcial circulante (Resende \& Barbosa, 2005). Com base em alguns aspectos técnicos e práticos, os autores sugerem o delineamento fatorial $3 \times 3$, por apresentar uma ótima eficiência seletiva, por permitir avaliar a capacidade geral de combinação e a prática de seleção dos genitores e por permitir um maior tamanho efetivo na população de seleção. Estas informações também são válidas para a seleção recorrente intrapopulacional em população sintética (SRIPS), porém, para seleção recorrente intrapopulacional (SRI) ou SRIPS, o delineamento em V (tipo de delineamento de cruzamento) é indicado quando os cruzamentos envolverem os genitores de maiores valores genéticos aditivos, visto que este delineamento permite cruzar os genitores superiores mais vezes (Resende, 2002). Para a população de $P$. caribaea var. hondurensis as duas estratégias de seleção poderão ser adotadas, bem como os delineamentos sugeridos.

Entre os genótipos mais divergentes será possível avaliar a capacidade específica e geral de combinação desses materiais, assim como, a heterose, devido aos efeitos aditivos e dominância, bem como a heterose funcional, com grande possibilidade de se obter genótipos mais produtivos que seus parentais.

\section{Conclusões}

A obtenção da distância generalizada de Mahalanobis e o agrupamento pelo método de Tocher forneceram informações que serão aplicadas para definir estratégias de cruzamento, visando um aumento de variabilidade genética em futuros testes de progênies.

Houve baixa divergência genética entre as progênies de P. caribaea var. caribaea.

$\mathrm{O}$ diâmetro à altura do peito foi o caráter que mais contribuiu para a distância genética entre as progênies de $P$. caribaea var. caribaea.

A maior proporção das progênies de $P$. caribaea var. caribaea agrupou-se em um único grupo a partir da otimização de Tocher. Para o desenvolvimento de híbridos intraespecíficos (cruzamentos controlados) serão priorizadas as progênies dos grupos heterogêneos de maiores valores genético e diâmetro a altura do peito.

\section{Referências}

ANUÁRIO estatístico ABRAF. Brasília, DF: ABRAF, 2011. 80 p.

CARVALHO, L. P.; LANZA, M. A.; FALLIERI, J.; SANTOS, J. W. Análise da divergência genética entre acessos de banco ativo de germoplasma de algodão. Pesquisa Agropecuária Brasileira, Brasília, DF, v. 38, n. 10, p. 1149-1155, 2003.

CRUZ, C. D. Programa GENES: versão Windows, aplicativo computacional em genética e estatística. Viçosa, MG: UFV, 2001. 648 p. 
CRUZ, C. D.; CARNEIRO, P. C. S. Modelos biométricos aplicados ao melhoramento genético. Viçosa, MG: UFV, 2003. v. 2. 585 p.

CRUZ, C. D.; REGAZZI, A. J. Modelos biométricos aplicados ao melhoramento genético. 2. ed. Viçosa, MG: UFV, 2001. 390 p.

DEMATTÊ, J. L. I. Levantamento detalhado dos solos do Câmpus experimental de Ilha Solteira. Piracicaba, SP: ESALQ/USP, 1980. 114 p. Mimeografado.

DIAS, L. A. Divergência genética e fenética multivariada na predição de híbridos e preservação de germoplasma de cacau (Theobroma cacao L.). 1994. 94 f. Tese (Doutorado) - Escola Superior de Agricultura "Luis de Queiroz", Universidade de São Paulo, Piracicaba, SP.

FERRAZ FILHO, P. B.; SILVA, L. O. C.; SOUZA, J. C.; MALHADO, C. H. M. Divergência genética de touros nelores com sêmen disponível em centrais de inseminação no Brasil. Archivos Latinoamericanos de Producción Animal, Mayaguez, v. 16, n. 1, p. 25-31, 2008.

FIER, I. S. N.; KIKUTI, P. Perspectivas para a utilização de espécies de Pinus spp. do México e América Central na região de Telêmaco Borba-PR. In: CONGRESSO FLORESTAL PANAMERICANO, 1., CONGRESSO FLORESTAL BRASILEIRO, 7., 1993, Curitiba. Anais... São Paulo: SBS, SBEF, 1993. v. 1. p. 139-143.

FOELKEL, C. E. B.; BRASIL, M. A. M.; BARRICHELA, L. G. E. Métodos para determinação da densidade básica de cavacos para coníferas e folhosas. IPEF, Piracicaba, SP, n. 2-3, p. 65-74, 1971.

FRANCIS, J. K. Pinus caribaea morelet. Caribbean pine. New Orleans: Department of Agriculture, Forest Service, Southern Forest Experiment Station. 1992. 10 p.

HERNANDEZ, F. B. T.; LEMOS FILHO, M. A. F.; BUZETTI, S. Software HIBRISA e o balanço hídrico de Ilha Solteira. Ilha Solteira: UNESP/FEIS, 1995. 45 p. (UNESP/FEIS/Área de Hidráulica e Irrigação. Série Irrigação, 1).

HUMPHREYS, M. O. A genetic approach to the multivariate differentiation of perennial ryegrass (Lolium perenne L.) populations. Heredity, London, v. 66, p. 437-443, 1991.

KAGEYAMA, P. Y. Variação genética entre procedências de Pinus oocarpa Schiede na região de Agudos, SP. 1977. 82 f. Dissertação (Mestrado) - Escola Superior de Agricultura "Luiz de Queiroz", Universidade de São Paulo, Piracicaba, SP.

MISSIO, R. F.; CAMBUIM, J.; MORAES, M. L. T.; PAULA, R. C. Seleção simultânea de caracteres em progênies de Pinus caribaea var. bahamensis. Scientia Forestalis, Piracicaba, SP, v. 66, p. 161168, 2004.

MISSIO, R. F.; MORAES, M. L. T.; DIAS, L. A. S. Efeito do desbaste seletivo sobre a divergência genética em progênies de Pinus caribaea Morelet var. bahamensis. Scientia Forestalis, Piracicaba, SP, v. 73, p. 27-36, 2007.

MORAES, M. L. T. Variação genética e aplicação da análise multivariada em progênies de Pinus caribaea Morelet var. hondurensis Barret e Golfari. 2001. 124 f. Tese (Livre-docência) - Faculdade de Engenharia de Ilha Solteira, Universidade Estadual Paulista "Júlio de Mesquita Filho", Ilha Solteira.
NEGREIROS, J. R. S., ALEXANDRE R. S.; ÁlVARES, V. S.; BRUCKNER, C. H.; CRUZ, C. D. Divergência genética entre progênies de maracujazeiro amarelo com base em características das plântulas. Revista Brasileira de Fruticultura, Jaboticabal, v. 30, n. 1, p. 197-201, 2008.

RESENDE, M. D. V.; HIGA, A. R. Estimação de valores genéticos no melhoramento de Eucalyptus: seleção em um caráter com base em informações do indivíduo e de seus parentes. Boletim de Pesquisa Florestal, Colombo, n. 28-29, p.11-36, 1994.

RESENDE, M. D. V.; BARBOSA, M. H. P. Melhoramento genético de plantas de propagação assexuada. Colombo: Embrapa Florestas, 2005. $130 \mathrm{p}$.

RESENDE, M. D. V. Genética biométrica e estatística no melhoramento de plantas perenes. Brasília, DF: Embrapa Informação Tecnológica, 2002. 975 p.

SILVA, J. M. Análises genéticas em progênies de Pinus caribaea Morelet var. caribaea por caracteres quantitativos e marcadores moleculares. 2005. 129 f. Dissertação (Mestrado) - Faculdade de Engenharia de Ilha Solteira, Universidade Estadual Paulista "Júlio de Mesquita Filho", Ilha Solteira.

SILVA JÚNIOR, F. G. Utilização múltipla da madeira de Pinus caribaea var. hondurensis para produção de celulose kraft. Série Técnica do IPEF, Piracicaba, SP, v. 9, n. 27, p. 56-62, 1993.

SINGH, D. The relative importance of characters affecting genetic divergence. The Indian Journal of Genetic and Plant Breeding, New Delhi, v. 41, p. 237-245, 1981.

SISTEMA brasileiro de classificação de solos. Brasília, DF: Embrapa Produção de Informação; Rio de Janeiro: Embrapa Solos, 1999. $412 \mathrm{p}$.

VIEIRA, E. A.; CARVALHO, F. I. F.; OLIVEIRA, A. C.; MARTINS, L. F.; BENIN, G.; SILVAS, J. A. G.; KOPP, M. M.; HARTWIG, I.; CARVALHO, M. F.; VALÉRIO, I. P. Associação da distância genética em trigo estimada a partir de caracteres morfológicos, caracteres fenológicos e dos componentes do rendimento de grãos. Revista Brasileira Agrociência, Pelotas, v. 13, n. 2, p. 161-168, 2007.

WANG, H.; MALCOLM, D. C.; FLETCHER, A. M. Pinus caribaea in China: introduction, genetic resources and future prospects. Forest Ecology and Management, Amsterdan, v. 117, p. 1-15, 1999.

ZHENG, Y. Q.; ENNOS, R. A. Genetic variabitity and structure of natural and domesticated populations of Caribbean pine (Pinus caribaea Morelet). Theoretical and Applied Genetics, Berlin, n. 98, p. 765-771, 1999.

ZHENG, Y. Q.; ENNOS, R. A.; WANG, H. R. Provenance variation and genetic parameters in a trial of Pinus caribaea Morelet var. 'bahamensis' Barr. and Golf. Forest Genetics, Zvolen, v. 1, p. 165-174, 1997. 
